\title{
Predictors of haematocrit in lumbar fusion for lumbar disc herniation: a surgical assessment
}

\author{
Qingchun Cai, Sixiang Zeng, Liqiang Zhi, Junlong Wu and Wei Ma*
}

\begin{abstract}
Background: Low haematocrit (Hct) is associated with a higher rate of post-operative complications, increased mortality, and additional medical costs following cardiac surgery. Predictors of post-operative Hct in lumbar fusion are unclear and may be beneficial in avoiding adverse surgical outcomes.

Methods: A total of 704 lumbar disc herniation patients (385 males, 319 females) who underwent primary lumbar fusion surgery were reviewed in this retrospective study.

Results: In the 687 patients who met the selection criteria, the pre-operative Hct was $41.23 \pm 4.57 \%$, the post-operative Hct was $32.61 \pm 4.52 \%$, the peri-operative Hct decline was $8.62 \pm 4.07 \%$, the estimated intra-operative blood loss was $586.76 \pm 346.62 \mathrm{~mL}$, and the post-operative drainage was $489.33 \pm 274.32 \mathrm{~mL}$. Pre-operative Hct, estimated blood volume, estimated intra-operative blood loss, post-operative drainage, allogeneic blood transfusion, and age showed significant correlations with post-operative Hct, and all factors were involved in the final multiple regression model. Patients who received intensive care had lower post-operative Hct values, and the length of post-operative hospital stay was negatively correlated with post-operative Hct.

Conclusions: Dangerously low post-operative Hct is related to the length of ICU stay and post-operative hospital stay. Age, pre-operative Hct, intra-operative blood loss, post-operative drainage, and units of allogeneic blood transfusion are significant predictors of post-operative Hct and Hct decline. Hct variations during the operation make the calculation of total blood loss difficult.
\end{abstract}

Keywords: Haematocrit, Posterior lumbar fusion, Surgical outcome, Haemorrhage

\section{Background}

Lumbar fusion rates have risen rapidly since the 1980s, a tendency driven by the approval of new surgery implants, enhanced diagnostic awareness, and a change in patient demand [1-5]. Posterior lumbar fusion is an effective therapy for primary lumbar disc herniation in patients suffering from chronic back pain or patients who suffer from concomitant canal stenosis, instability associated with radiculopathy, extreme lateral prolapse of a lumbar intervertebral disc, or multiple disc herniation; this procedure is conventionally performed at many medical institutions $[6,7]$. Several published studies have

\footnotetext{
*Correspondence: mawei60@126.com

Department of Orthopedics, First Affiliated Hospital of Medical College, Xi'an Jiaotong University, 277 Yanta West Street, Xi'an 710061, Shaanxi, People's Republic of China
}

indicated that the volume of peri-operative blood loss causes lower post-operative Hct, which is associated with a higher rate of post-operative complications, increased mortality, and additional medical expenditures [13-18]. When massive haemorrhage occurs during surgery, crystalloid and colloidal solutions are applied to maintain intravascular volume and improve microcircution; furthermore, blood products are necessary to ennce the ability to carry oxygen and improve the blood function if haemorrhage is unremitting. wever, standard liquid management and allogeneic od transfusion have the opposite effect on Hct, which hinders the prediction of post-operative Hct. The Hct level is a crucial variable for the calculation of total 
blood loss. Therefore, this study attempted to answer several questions: 1) Is a lower Hct level associated with poor surgical outcomes in lumbar fusion? 2) What are the dominant predictors of post-operative Hct? 3) Do variations in Hct affect the routine method for calculating total blood loss?

\section{Methods}

\section{Case sourcing and selection}

The cohort in this retrospective study included patients who had undergone posterior lumbar fusion because of lumbar disc herniation between June 2009 and September 2014. The inclusion criteria were as follows: a diagnosis of lumbar disc herniation or in parallel with lumbar canal stenosis, a primary surgical procedure combined with decompression, discectomy, intervertebral or intertransverse lumbar fusion, and internal fixation with a pedicle screw performed under general anaesthesia. The exclusion criteria were as follows: revision surgery, clotting abnormalities or anticoagulant use in the week prior to surgery, use of blood conservation strategies, multiple incisions, and leakage of cerebrospinal fluid intra-operatively or post-operatively.

\section{Collection of variables}

Demographic data from the patients were collected as follows: month of admission, age, sex, contact details, height and weight. The hospital and surgical data collected included the following: smoking history, alcohol history, body mass index (BMI), liver disease, anaemia, Charlson Comorbidity Index (CCI) [19], ASA physical status classes index (ASA), National Nosocomial Infections Surveillance (NNIS) (pre-assessment scale), surgery segments, surgeon-estimated volume of intraoperative blood loss, anaesthetist-estimated volume of intra-operative blood loss, units of allogeneic blood transfusion (units of ABT), pre-operative Hct (Hct[Pre]), pre-operative haemoglobin ( $\mathrm{Hb}[$ pre]), post-operative Hct (Hct[Post]), post-operative haemoglobin ( $\mathrm{Hb}[$ post]), postoperative drainage (PD), length of post-operative hospital stay (Length of Post-op Hos stay), length of ICU stay, occurrence of redo surgery, wound infection, urinary infection, pneumonia, sepsis, myocardial infarction, deep vein thrombosis, pulmonary embolism, and post-operative death. The transfusion triggers at the authors' institution were as follows: 1) haemoglobin level less than $9 \mathrm{~g} / \mathrm{dL} ; 2$ ) symptomatic anaemia (shortness of breath, fatigue, dizziness, decreased exercise tolerance, and so on); and 3) a liberal transfusion trigger adopted when inadequate oxygenation would exacerbate the patient's pre-existing complication [20, 21]. The principle of liquid therapy at the institution conformed to the standards in the review by Sweeney [22] and the latest intravenous liquid therapy guidelines developed by the National Clinical Guideline
Center [23]. A routine surgical procedure was performed by several senior spinal surgeons for all of the reviewed patients, and the application of intervertebral lumbar fusion or intertransverse lumbar fusion was performed according to their judgement. The surgeon and anaesthetist separately estimated the intra-operative blood loss through weighing sponges, suction drainage and errhysis from the surgical field. Negative pressure drainage was used for all patients to prevent post-operative haematoma and associated neurologic compromise [24], and the drainage was removed 2 or 3 days after surgery. The haemoglobin and Hct data were derived from routine preoperative and post-operative blood tests. The blood samples were prepared by nurses with an EDTAK blood anticoagulant tube before surgery and after the drainage was removed. The blood samples were immediately delivered to the laboratory and analysed with a Sysmex HST302 or Sysmex HST201 automatic blood cell analysis assembly line.

\section{Calculation of blood loss}

The average of volume of intra-operative blood loss estimated by the surgeon and by the anaesthetist was calculated as estimated intra-operative blood loss (EBL[intra]).

The calculation of blood volume was based on the classic method developed by Nadler and colleagues [25]:

$\mathrm{EBV}=\mathrm{K} 1$ *height $(\mathrm{m})^{3}+\mathrm{K} 2$ *weight $(\mathrm{kg})+\mathrm{K} 3$.

$[\mathrm{K} 1=0.3669, \mathrm{~K} 2=0.03219, \mathrm{~K} 3=0.6041$ for males and $\mathrm{K} 1=0.3561, \mathrm{~K} 2=0.03308$, and $\mathrm{K} 3=0.1833$ for females].

To maintain dimensional consistency, the EBV was converted to the estimated blood volume in millilitres $(\mathrm{EBV}[\mathrm{mL}]): \mathrm{EBV}(\mathrm{mL})=\mathrm{EBV}^{*} 1000$.

The Hct decline was calculated as follows:

Hct Decline $=$ Hct (pre)-Hct (post).

[Hct Decline is the scale of Hct decline during perioperation, Hct (pre) is pre-operative Hct, and Hct (post) is post-operative Hct].

\section{Statistical analysis}

The statistical analysis was performed with IBM SPSS statistics software version 19 (IBM Co, Armonk, NY, USA). The measurement data are shown as the mean \pm standard deviation, and the qualitative and ordinal data were demonstrated as frequency distributions. The independent sample t-test was applied to compare post-operative Hct changes between two different groups. One-way ANOVA analysis was applied to compare post-operative Hct changes among three or more groups. If the test of homogeneity of variance was inappropriate, the Kruskal-Wallis test was applied for multiple independent samples of non-parametric tests. Pearson's correlation coefficient was used to explore the correlation between continuous variables. Multiple linear 
regression was used to explore the predictors of postoperative Hct with a stepwise regression strategy while controlling for smoking, alcohol drinking, anaemia and NNIS. Throughout data analysis, $P<0.05$ was considered statistically significant.

\section{Results}

A total of 687 lumbar disc herniation patients (375 males, 312 females) of the 704 reviewed patients met the selection criteria. The statistical descriptions of the demographic data, hospital data, and surgery data are provided in Tables 1 and 2. The EBV $(\mathrm{mL})$ was $4268.57 \pm 665.11 \mathrm{~mL}$, the EBL(intra) was $586.76 \pm 346.62 \mathrm{~mL}$, the volume of PD was $489.33 \pm 274.32 \mathrm{~mL}$, and the units of ABT were 1.49. Most patients (68.0\%) scored two points on the ASA physical status classes index assessment. A total of 342 patients (49.8\%) underwent fusion surgery of a single segment, 292 patients $(42.5 \%)$ underwent fusion surgery of two segments, and the remaining 53 patients (7.7\%) underwent fusion surgery of three or four segments.

\section{Post-operative Hct}

The HCT(pre) was $41.23 \pm 4.57 \%$, and the $\mathrm{HCT}$ (post) was $32.61 \pm 4.52 \%$. The post-operative Hct of the male subjects was $34.54 \pm 4.32 \%$, which was higher than that

Table 1 Description of quantitative data

\begin{tabular}{lllll}
\hline & Minim & Maximum & Mean & Std-deviation \\
\hline Age $(\mathrm{Y})$ & 18 & 80 & 52.86 & 12.38 \\
Height $(\mathrm{cm})$ & 1.45 & 1.86 & 1.67 & 0.07 \\
Weight $(\mathrm{Kg})$ & 40 & 126 & 66.40 & 11.16 \\
BMI index $\left(\mathrm{Kg} / \mathrm{m}^{2}\right)$ & 15.63 & 38.89 & 23.78 & 3.25 \\
BL(surgeon) $(\mathrm{mL})$ & 50 & 2800 & 574.35 & 337.81 \\
BL(anaesthetist) $(\mathrm{mL})$ & 50 & 2800 & 599.17 & 375.67 \\
EBL(intra) $(\mathrm{mL})$ & 75 & 2800 & 586.76 & 346.62 \\
PD (mL) & 50 & 2065 & 489.33 & 274.32 \\
Units of ABT $(\mathrm{U})$ & 0 & 11 & 1.49 & 1.84 \\
Hb(pre) $(\mathrm{g} / \mathrm{L})$ & 85 & 188 & 137.74 & 16.79 \\
Hct(pre) $(\%)$ & 28.7 & 72.4 & 41.23 & 4.57 \\
Hb(post) $(\mathrm{g} / \mathrm{L})$ & 72 & 164 & 109.2 & 16.14 \\
Hct (post) $(\%)$ & 21.3 & 46.7 & 32.61 & 4.52 \\
Hct Decline(\%) & -4.2 & 35.6 & 8.62 & 4.07 \\
EBV(mL) & 2625.20 & 6799.80 & 4268.57 & 665.11 \\
Length of Post-op & 3 & 86 & 12.4 & 5.8 \\
Hos Stay (Day) & & & & \\
\hline BL (surgon) & & &
\end{tabular}

$B L$ (surgeon) volume of intra-operative blood loss estimated by the surgeon, $B L$ (anaesthetist) volume of intra-operative blood loss estimated by the anaesthetist, $E B L$ (intra) estimated intra-operative blood loss, $P D$ post-operative drainage, Units of $A B T$ units of allogenic red blood cell transfusion, $H b$ (pre) pre-operative haemoglobin, $\mathrm{Hct}$ (pre) pre-operative haematocrit, $\mathrm{Hb}$ (post) post-operative haemoglobin, $H c t$ (post) post-operative haematocrit, Hct decline decline of haematocrit, $E B V(\mathrm{~mL})$ estimated blood volume in millilitres, Length of Post-op Hos Stay The length of the post-operative hospital stay of the females $(p<0.001)$, and patients with a history of smoking, alcohol abuse or anaemia had lower postoperative Hct $(p<0.001)$. The post-operative Hct change decreased significantly as the fusion segments increased (Table 2). Age, BMI, EBV $(\mathrm{mL})$, Hct(pre), EBL(intra) and PD showed statistical correlations with post-operative Hct in the Pearson correlation analysis (Table 3). Six factors were involved in the ultimate multiple regression model of post-operative Hct (in accordance with the standard coefficient): Hct(pre), $\mathrm{BL}$ (intra), units of $\mathrm{ABT}, \mathrm{PD}, \mathrm{EBV}(\mathrm{mL})$, and age. This model explained $53 \%$ of the post-operative Hct $\left(R^{2}=0.530\right)($ Table 4).

\section{Hct decline}

The peri-operative Hct decline was $8.62 \pm 4.07 \%$. The extent of the decline in peri-operative Hct was significantly different according to gender and surgery segments. Anaemia caused a smaller decline in Hct (Table 2). The Pearson correlation analysis revealed that the Hct decline was positively correlated with age, EBV(mL), Hct (pre), EBL (intra), and PD (Table 3). A multiple regression equation for Hct decline was established, and the equation included the following predictors: Hct (pre), PD, gender, EBL (intra), units of ABT, BMI, and age (Table 4).

\section{Average Hct}

Average Hct was defined as the average between the pre-operative Hct and post-operative Hct. The average Hct also had a negative correlation with EBL(intra) and $\mathrm{PD}$, indicating that more peri-operative blood loss was associated with a lower average Hct. Age, BMI, and $\mathrm{EBV}(\mathrm{mL})$ were also statistically correlated with average Hct (Table 3).

\section{Surgical outcomes}

The length of post-operative hospital stay was $12.4 \pm 5.8$ days; 67 patients $(9.8 \%)$ received intensive care, and the mean length of ICU stay was $2.5 \pm 1.0$ days. A total of 11 patients (1.6\%) underwent redo surgeries, 26 patients $(3.8 \%)$ suffered from wound infection, and 5 $(0.7 \%)$ and $3(0.4 \%)$ patients encountered urinary infection and pneumonia, respectively. One patient suffered from deep vein thrombosis, but no patients experienced sepsis, pulmonary embolism or post-operative death. Patients who received intensive care had lower postoperative Hct; patients who underwent redo surgeries had smaller Hct declines; and the length of postoperative hospital stay had a negative correlation with post-operative Hct and average Hct (Tables 2 and 3).

\section{Discussion}

The intra-operative blood loss was $586.76 \pm 346.62 \mathrm{~mL}$, which was less than the $907 \pm 775 \mathrm{~mL}$ estimated blood 
Table 2 Post-operative haematocrit and haematocrit decline among different groups

\begin{tabular}{|c|c|c|c|c|c|c|}
\hline & & Frequency & Hct(post) (\%) & $P$ value & Hct decline (\%) & $P$ value \\
\hline \multirow[t]{2}{*}{ Gender } & Male & $375(54.6 \%)$ & $34.54 \pm 4.32$ & $<0.001$ & 9.20 & $<0.001$ \\
\hline & Female & $312(45.4 \%)$ & $30.30 \pm 3.58$ & & 7.92 & \\
\hline \multirow[t]{2}{*}{ Smoking } & Yes & $189(27.5 \%)$ & $34.70 \pm 4.21$ & $<0.001$ & 8.85 & .365 \\
\hline & No & 498(72.5\%) & $31.82 \pm 4.38$ & & 8.53 & \\
\hline \multirow[t]{2}{*}{ Alcohol Drinking } & Yes & $43(6.3 \%)$ & $35.31 \pm 4.29$ & $<0.001$ & 8.91 & .631 \\
\hline & No & 644(93.7\%) & $32.43 \pm 4.48$ & & 8.60 & \\
\hline \multirow[t]{2}{*}{ Liver Disease } & Yes & $12(1.7 \%)$ & $32.28 \pm 3.96$ & .799 & 8.86 & .837 \\
\hline & No & 675(98.3\%) & $32.62 \pm 4.53$ & & 8.61 & \\
\hline \multirow[t]{2}{*}{ Anaemia } & Yes & $32(4.7 \%)$ & $27.86 \pm 2.46$ & $<0.001$ & 4.95 & $<0.001$ \\
\hline & No & 655(95.3\%) & $32.85 \pm 4.47$ & & 8.80 & \\
\hline \multirow[t]{5}{*}{$\mathrm{CCl}$} & 0 & $462(67.2 \%)$ & $32.88 \pm 4.47$ & .103 & 8.51 & .684 \\
\hline & 1 & $162(23.6 \%)$ & $31.86 \pm 4.46$ & & 8.95 & \\
\hline & 2 & $53(7.7 \%)$ & $32.91 \pm 5.08$ & & 8.49 & \\
\hline & 3 & $9(1.3 \%)$ & $30.88 \pm 3.92$ & & 9.18 & \\
\hline & 5 & $1(0.1 \%)$ & 31.70 & & 9.80 & \\
\hline \multirow[t]{4}{*}{ ASA } & 1 & 137(19.9\%) & $33.42 \pm 4.69$ & .018 & 8.38 & .217 \\
\hline & 2 & $467(68.0 \%)$ & $32.46 \pm 4.43$ & & 8.70 & \\
\hline & 3 & 79(11.5\%) & $31.90 \pm 4.55$ & & 8.73 & \\
\hline & 4 & $4(0.6 \%)$ & $36.70 \pm 3.70$ & & 5.1 & \\
\hline \multirow[t]{3}{*}{ NNIS } & 0 & $516(75.1 \%)$ & $32.81 \pm 4.55$ & .096 & 8.40 & .043 \\
\hline & 1 & $162(23.6 \%)$ & $31.95 \pm 4.38$ & & 9.44 & \\
\hline & 2 & $9(1.3 \%)$ & $33.19 \pm 4.74$ & & 6.29 & \\
\hline \multirow[t]{4}{*}{ Surgery Segments } & 1 & $342(49.8 \%)$ & $33.26 \pm 4.43$ & $<0.001$ & 7.94 & $<0.001$ \\
\hline & 2 & $292(42.5 \%)$ & $32.16 \pm 4.54$ & & 9.10 & \\
\hline & 3 & $48(7.0 \%)$ & $30.78 \pm 4.45$ & & 10.70 & \\
\hline & 4 & $5(0.7 \%)$ & $32.48 \pm 2.65$ & & 7.04 & \\
\hline \multirow[t]{2}{*}{ Length of ICU Stay } & YES & $67(9.8 \%)$ & $31.42 \pm 4.06$ & 0.022 & 8.93 & 0.507 \\
\hline & NO & $620(90.2 \%)$ & $32.74 \pm 4.55$ & & 8.58 & \\
\hline \multirow[t]{2}{*}{ Occurrence of Redo Surgery } & YES & $11(1.6 \%)$ & $33.36 \pm 4.99$ & 0.580 & 5.64 & 0.014 \\
\hline & NO & $676(98.4 \%)$ & $32.60 \pm 4.52$ & & 8.67 & \\
\hline \multirow[t]{2}{*}{ Wound Infection } & YES & $26(3.8 \%)$ & $31.13 \pm 4.12$ & 0.089 & 8.09 & 0.499 \\
\hline & NO & $661(96.2 \%)$ & $32.67 \pm 4.53$ & & 8.64 & \\
\hline
\end{tabular}

Hct (post) post-operative haematocrit, HCT decline decline of haematocrit, CCI Charlson Comorbidity Index, ASA American Society of Anaesthesiologists Physical Status Classes Index, NNIS National Nosocomial Infections Surveillance (pre-assessment scale)

loss during posterior spinal fusion for adolescent idiopathic scoliosis [11]. Several published studies have confirmed that an increased number of fusion segments increases the volume of intra-operative blood loss $[10,12,26-28]$. In this study, $92.3 \%$ of patients underwent a one or two segment fusion procedure, whereas only five patients underwent the highest four segment fusion procedure. Thus, fewer fusion segments explained the lower intra-operative blood loss. The volume of postoperative drainage was larger than that reported in a study performed by Zou, which involved one-segment or twosegment lumbar spinal surgery [29]. In the present study, the negative pressure type drainage influenced the volume of post-operative drainage; furthermore, not all patients underwent lumbar fusion procedures in Zou's study. Taken together, these data suggest that more surgery segments led to more peri-operative blood loss.

To measure the effect of these collected variables on post-operative Hct, a multiple regression analysis was performed. The multiple regression model of post-operative Hct showed the following: 1) pre-operative Hct had the most predictive effect on post-operative Hct in this model; 2) post-operative drainage and intra-operative blood loss were important predictors for post-operative Hct on the 
Table 3 Pearson correlation analysis about post-operative haematocrit, haematocrit decline and average haematocrit

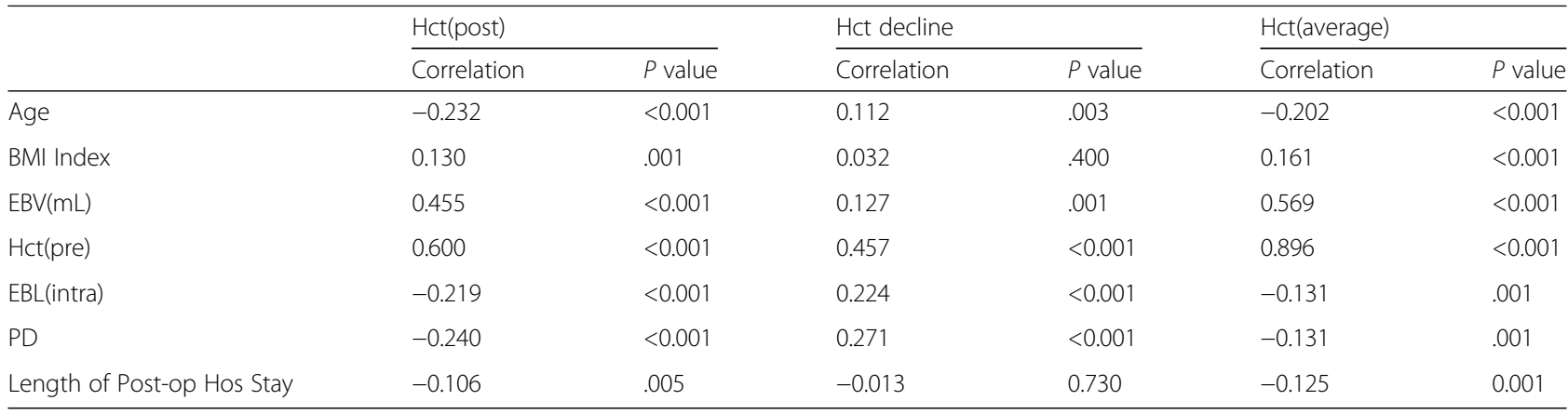

Hct (post) post-operative haematocrit, Hct (average) the average of pre-operative haematocrit and post-operative haematocrit, Hct decline decline of haematocrit, EBV $(\mathrm{mL}$ ) estimated blood volume in millilitres, Hct (pre) pre-operative haematocrit, EBL (intra) estimated intra-operative blood loss, PD post-operative drainage, Length of Post-op Hos Stay The length of the post-operative hospital stay

basis of standardised coefficients; 3) a prudent transfusion strategy and elderly resulted in lower post-operative Hct. Lee reported that post-operative Hct was not correlated with age, BMI, or anaesthesia type [30]. However, Wang and Hannan suggested that age may be associated with changes in peri-operative Hct $[13,31]$. With a stepwise strategy, age was entered in the multiple regression model in this study but had a very weak prediction effect. Additionally, females had lower post-operative Hct, although the extent of Hct decline was less obvious mathematically because females had lower pre-operative Hct.

Increased haemodilution is associated with vital organ dysfunction, other peri-operative complications, an increase in post-operative mortality, and greater consumption of medical resources in cardiac and non-cardiac surgery [13-18]. A published animal experiment study also confirmed that a lower Hct level was associated with lower perfusion pressure, increased fluid retention, and worse cerebrovascular injury after deep hypothermic circulatory arrest [32]. In the present study, patients who received intensive care had lower post-operative Hct; the length of post-operative hospital stay was negatively correlated with post-operative Hct and average Hct. These data indicated that patients with lower postoperative Hct required more medical expenditure, which is consistent with results from previous studies. Interestingly, patients who underwent redo surgeries had a lesser Hct decline. After a comprehensive review of these cases, 8 of the 11 patients underwent redo surgeries for symptomatic epidural haematoma, which signified that the post-operative drainage was insufficient and caused a lesser Hct decline. Considering the low incidence of urinary infection, pneumonia, sepsis, deep vein thrombosis, pulmonary embolism and post-operative

Table 4 Multiple regression analysis model about post-operation haematocrit and haematocrit decline

\begin{tabular}{llllr}
\hline & & Unstandardized coefficient & Standardized coefficient & VIF square \\
\hline Hct (post) & Constant & 11.181 & 0.509 & 0.53 \\
& Hct(pre) & 0.504 & -0.231 & 1.512 \\
PD & -0.004 & 0.213 & 1.266 \\
EBV(mL) & 0.001 & -0.434 & 2.484 \\
EBL(intra) & -0.006 & 0.414 & 2.573 \\
Units of ABT & 1.016 & -0.096 & 1.126 \\
Hct Decline & -0.035 & & 0.42 \\
& Age & -13.690 & 0.576 & 1.702 \\
& Constant & 0.513 & 0.256 & 1.266 \\
Hct(pre) & 0.004 & -0.216 & 1.602 \\
PD & -1.760 & 0.482 & 2.642 \\
Gender & 0.006 & -0.451 & 2.702 \\
EBL(intra) & -0.996 & -0.123 & 1.080 \\
Units of ABT & -0.153 & 0.121 & 1.138 \\
\hline
\end{tabular}

VIF variance inflation factor, $H c t$ (post) post-operative haematocrit, $H c t$ decline decline of haematocrit, $H c t$ (pre) pre-operative haematocrit, $P D$ post-operative drainage, $E B V(m L)$ estimated blood volume in millilitres, $E B L$ (intra) estimated intra-operative blood loss, Units of ABT units of allogenic red blood cell transfusion 
death in lumbar fusion, larger samples are needed to explore the relationship between these events and postoperative Hct.

Both the Pearson correlation analysis and multiple regression analysis regarding Hct decline showed that age, Hct(pre), EBL(intra) and PD were positively correlated with Hct decline. It is evident that Hct declines to a greater extent when more blood is lost during surgery. However, the positive correlation between Hct decline and Hct(pre) is puzzling. Considering that there is no consistent blood transfusion threshold, a lower chance of receiving blood transfusion peri-operatively may contribute to a greater decline in Hct among patients with a higher pre-operative Hct. The negative standardised coefficient of units of ABT in the Hct decline multiple regression model also confirmed this conjecture from another aspect. This means that appropriate blood transfusion is very important for avoiding lower Hct. Therefore, a liberal transfusion strategy should be applied to patients who undergo lumbar fusion with three or more segments to avoid lower post-operative Hct due to the relationship between post-operative Hct and the length of post-operative hospital stay/ICU stay. Yoshihara and Jans found that pre-operative anaemia was a significant predictor of allogeneic blood transfusion in hip and knee arthroplasty [33, 34]. Patients diagnosed with anaemia had less of a decline in peri-operative Hct, perhaps because of the change in blood transfusion strategy.

Following the method developed by Gross et al., many published studies have calculated total blood loss as follows: total blood loss = estimated blood volume* (preoperative Hct - post-operative Hct)/the average Hct [35-39]. This formula calculates the volume of red blood cell loss according to pre-operative Hct and post-operative Hct and then converts the volume of red blood cell loss into the volume of blood loss using the average Hct. As the Pearson correlation analysis of average Hct showed, greater peri-operative haemorrhage causes a lower average Hct level (see details in Table 3). Based on the aforementioned formula, the volume of blood loss is converted by lower average Hct when more haemorrhage occurs, which means that the same calculated volume of blood loss would contain different volumes of red blood cells due to different average Hct. A differential red blood cell proportion indicates a different oxygen delivery ability. The other problem is that this formula was originally used to estimate allowable pre-transfusion blood loss, so only the influences of blood loss and fluid management on the fluctuation of peri-operation Hct were considered. In such a simplified mathematical model, the Hct declines linearly during surgery. However, the effects of allogeneic transfusion and blood conservation strategies on Hct, which could affect the accuracy of the blood loss calculation, were ignored.

\section{Conclusion}

Lower post-operative Hct is correlated with ICU stay and the length of post-operative hospital stay. Age, preoperative Hct, intra-operative blood loss, post-operative drainage, and units of allogeneic blood transfusion are significant predictors of post-operative Hct and Hct decline. Adoption of a liberal transfusion strategy in further studies is needed to enforce guidelines for its use in lumbar fusion surgeries with multiple segments. The fluctuation in Hct is influenced by the volume of blood loss, liquid therapy, blood product transfusion, and other blood conservation strategies that make the routine calculation method for total blood loss inaccurate.

\section{Abbreviations}

ABT [intra]: Volume of intra-operative allogeneic blood transfusion; ABT[post]: Post-operative allogeneic blood transfusion; ASA: ASA physical status classes index; BL[anaesthetist]: Volume of intra-operative blood loss estimated by the anaesthetist; BL[surgeon]: Volume of intra-operative blood loss estimated by the surgeon; BMI index: Body mass index; CCl: Charlson Comorbidity Index; EBL (intra): Estimated intra-operative blood loss; EBV $(\mathrm{mll})$ : Estimated blood volume in millilitres; EBV: Estimated blood volume; $\mathrm{Hb}$ [post]: Post-operative haemoglobin; Hb [pre]: Pre-operative haemoglobin; Hct [Pre]: Pre-operative haematocrit; Hct decline: Decline of haematocrit; Hct[Post]: Post-operative haematocrit; Length of Post-op Hos Stay: The length of the post-operative hospital stay; NNIS: National Nosocomial Infections Surveillance; PD: Post-operative drainage; units of ABT: The sum of $A B T$ (intra) and $A B T$ (post)

\section{Acknowledgements}

This investigation was performed with the assistance of the Medical Records Room, First Affiliated Hospital of Medical College, Xi'an Jiaotong University.

\section{Funding \\ Not applicable.}

\section{Availability of data and materials}

Most relevant data are contained within the paper, and the raw data are freely available in an Excel spreadsheet format upon request from the corresponding author.

\section{Authors' contributions}

QCC contributed to the design of the study, acquisition of data, analysis and interpretation of data, and drafting the article. SXZ, LQZ and JLW contributed to acquisition of data and analysis. WM contributed the conception and design of the study, analysis of data, and drafting the article. All authors read and approved the final manuscript.

\section{Ethics approval and consent to participate}

This study was approved by the local ethics committee (First Affiliated Hospital of Medical College, Xi'an Jiaotong University) and was conducted in accordance to the 1964 Helsinki Declaration and its later amendments. The local ethics committee specifically approved that informed consent was not required because data were going to be analysed anonymously.

\section{Consent for publication}

Not applicable.

\section{Competing interests}

The authors declare that they have no competing interests.

\section{Publisher's Note}

Springer Nature remains neutral with regard to jurisdictional claims in published maps and institutional affiliations. 
Received: 14 September 2015 Accepted: 4 July 2017 Published online: 01 August 2017

\section{References}

1. Katz JN, Spratt KF, Andersson GB, Boden SD, Fraser RD, Garfin SR, et al. Epidemiology introduction. 1995 Focus Issue Meeting on Fusion. Spine. 1995;20(24 Suppl):76S-7S.

2. Deyo RA, Mirza SK. Trends and variations in the use of spine surgery. Clin Orthop Relat Res. 2006:443:139-46.

3. Pannell WC, Savin DD, Scott TP, Wang JC, Daubs MD. Trends in the surgical treatment of lumbar spine disease in the United States. Spine J. 2015;15(8): 1719-1727.

4. Deyo RA, Gray DT, Kreuter W, Mirza S, Martin BI. United States trends in lumbar fusion surgery for degenerative conditions. Spine. 2005;30(12):1441-5. discussion 6-7.

5. Yoshihara $\mathrm{H}$, Yoneoka D. National trends in the surgical treatment for lumbar degenerative disc disease: United States, 2000 to 2009. Spine J. 2015;15(2):265-71.

6. Wang JC, Dailey AT, Mummaneni PV, Ghogawala Z, Resnick DK, Watters WC 3rd, et al. Guideline update for the performance of fusion procedures for degenerative disease of the lumbar spine. Part 8: lumbar fusion for disc herniation and radiculopathy. J Neurosurg Spine. 2014;21(1):48-53.

7. Lee CK, Langrana NA. A review of spinal fusion for degenerative disc disease: need for alternative treatment approach of disc arthroplasty? Spine J. 2004;4(6 Suppl):173S-6S.

8. Elgafy H, Bransford RJ, McGuire RA, Dettori JR, Fischer D. Blood loss in major spine surgery: are there effective measures to decrease massive hemorrhage in major spine fusion surgery? Spine. 2010;35(9 Suppl):S47-56.

9. Hu SS. Blood loss in adult spinal surgery. Eur Spine J. 2004;13(Suppl 1):S3-5.

10. Zheng F, Cammisa FP Jr, Sandhu HS, Girardi FP, Khan SN. Factors predicting hospital stay, operative time, blood loss, and transfusion in patients undergoing revision posterior lumbar spine decompression, fusion, and segmental instrumentation. Spine. 2002;27(8):818-24.

11. Ialenti MN, Lonner BS, Verma K, Dean L, Valdevit A, Errico T. Predicting operative blood loss during spinal fusion for adolescent idiopathic scoliosis. J Pediatr Orthop. 2013;33(4):372-6.

12. Nuttall GA, Horlocker TT, Santrach PJ, Oliver WC Jr, Dekutoski MB, Bryant S. Predictors of blood transfusions in spinal instrumentation and fusion surgery. Spine. 2000;25(5):596-601.

13. Hannan EL, Samadashvili Z, Lahey SJ, Culliford AT, Higgins RS, Jordan D, et al. Predictors of postoperative hematocrit and association of hematocrit with adverse outcomes for coronary artery bypass graft surgery patients with cardiopulmonary bypass. J Card Surg. 2010;25(6):638-46.

14. Habib RH, Zacharias A, Schwann TA, Riordan CJ, Durham SJ, Shah A. Adverse effects of low hematocrit during cardiopulmonary bypass in the adult: should current practice be changed? I Thorac Cardiovasc Surg. 2003;125(6):1438-50.

15. Carrascal $Y$, Valenzuela H, Laguna G, Pareja P, Blanco M, Ortega C. Aortic valve surgery in octogenarians: Risk factors and long-term impact. Rev Clin Esp. 2015;215(3):148-55.

16. Ranucci M, Romitti F, Isgro G, Cotza M, Brozzi S, Boncilli A, et al. Oxygen delivery during cardiopulmonary bypass and acute renal failure after coronary operations. Ann Thorac Surg. 2005;80(6):2213-20.

17. Yavuz C, Demirtas S, Caliskan A, Ertas F, Kaya H, Aydin M, et al. The predictors of poor outcomes in patients with femoral artery injuries. Eur Rev Med Pharmacol Sci. 2013;17(14):1901-8.

18. Hogue CW Jr, Goodnough LT, Monk TG. Perioperative myocardial ischemic episodes are related to hematocrit level in patients undergoing radical prostatectomy. Transfusion. 1998;38(10):924-31.

19. Charlson ME, Pompei P, Ales KL, Mackenzie CR. A new method of classifying prognostic comorbidity in longitudinal studies: development and validation. J Chronic Dis. 1987;40(5):373-83.

20. Sharma S, Sharma P, Tyler LN. Transfusion of blood and blood products: indications and complications. Am Fam Physician. 2011;83(6):719-24.

21. American Society of Anesthesiologists Task Force on Perioperative Blood T, Adjuvant T. Practice guidelines for perioperative blood transfusion and adjuvant therapies: an updated report by the American Society of Anesthesiologists Task Force on Perioperative Blood Transfusion and Adjuvant Therapies. Anesthesiology. 2006;105(1):198-208.

22. Sweeney RM, McKendry RA, Bedi A. Perioperative intravenous fluid therapy for adults. Ulster Med J. 2013;82(3):171-8.
23. National Clinical Guideline C. National Institute for Health and Clinical Excellence: Guidance. Intravenous Fluid Therapy: Intravenous Fluid Therapy in Adults in Hospital. London: Royal College of Physicians (UK), National Clinical Guideline Centre; 2013.

24. Kanayama M, Oha F, Togawa D, Shigenobu K, Hashimoto T. Is closed-suction drainage necessary for single-level lumbar decompression?: review of 560 cases. Clin Orthop Relat Res. 2010;468(10):2690-4.

25. Nadler SB, Hidalgo JH, Bloch T. Prediction of blood volume in normal human adults. Surgery. 1962;51(2):224-32.

26. Guay J, Haig M, Lortie L, Guertin MC, Poitras B. Predicting blood loss in surgery for idiopathic scoliosis. Can J Anaesth. 1994;41(9):775-81.

27. Lenoir B, Merckx P, Paugam-Burtz C, Dauzac C, Agostini MM, Guigui P, et al. Individual probability of allogeneic erythrocyte transfusion in elective spine surgery: the predictive model of transfusion in spine surgery. Anesthesiology. 2009;110(5):1050-60.

28. Yoshihara $\mathrm{H}$, Yoneoka D. Predictors of allogeneic blood transfusion in spinal fusion in the United States, 2004-2009. Spine. 2014;39(4):304-10.

29. Zou H, Li Z, Sheng H, Tan M, Yang F, Liang L, et al. Intraoperative blood loss, postoperative drainage, and recovery in patients undergoing lumbar spinal surgery. BMC Surg. 2015;15:76.

30. Lee CB, Kalish LA, Millis MB, Kim YJ. Predictors of blood loss and Hct after periacetabular osteotomy. Hip Int. 2013;23(Suppl 9):S8-13.

31. Wang J, Wei J, Wang M. The risk factors of perioperative hemoglobin and hematocrit drop after intramedullary nailing treatment for intertrochanteric fracture patients. J Orthop Sci. 2015;20(1):163-7.

32. Shum-Tim D, MacDonald D, Takayuki S, Laliberte E, Chen J, Jamal AM, et al. Low postoperative hematocrit increases cerebrovascular damage after hypothermic circulatory arrest. Pediatr Crit Care Med. 2005;6(3):319-26.

33. Yoshihara $\mathrm{H}$, Yoneoka D. Predictors of allogeneic blood transfusion in total hip and knee arthroplasty in the United States, 2000-2009. J Arthroplast. 2014;29(9):1736-40.

34. Jans $\mathrm{O}$, Jorgensen $\mathrm{C}$, Kehlet $\mathrm{H}$, Johansson PI. Role of preoperative anemia for risk of transfusion and postoperative morbidity in fast-track hip and knee arthroplasty. Transfusion. 2014;54(3):717-26.

35. Gross JB. Estimating allowable blood loss: corrected for dilution. Anesthesiology. 1983;58(3):277-80.

36. Sehat KR, Evans $\mathrm{R}$, Newman JH. How much blood is really lost in total knee arthroplasty? - Correct blood loss management should take hidden loss into account. Knee. 2000;7(3):151-5.

37. Smorgick Y, Baker KC, Bachison CC, Herkowitz HN, Montgomery DM, Fischgrund JS. Hidden blood loss during posterior spine fusion surgery. Spine J. 2013;13(8):877-81.

38. Liu $X$, Zhang $X$, Chen $Y$, Wang $Q$, Jiang $Y$, Zeng B. Hidden blood loss after total hip arthroplasty. J Arthroplast. 2011;26(7):1100-5. e1.

39. Singla A, Malhotra R, Kumar V, Lekha C, Karthikeyan G, Malik V. A Randomized Controlled Study to Compare the Total and Hidden Blood Loss in ComputerAssisted Surgery and Conventional Surgical Technique of Total Knee Replacement. Clin Orthopedic Surg. 2015;7(2):211-6.

\section{Submit your next manuscript to BioMed Central and we will help you at every step:}

- We accept pre-submission inquiries

- Our selector tool helps you to find the most relevant journal

- We provide round the clock customer support

- Convenient online submission

- Thorough peer review

- Inclusion in PubMed and all major indexing services

- Maximum visibility for your research

Submit your manuscript at www.biomedcentral.com/submit
Biomed Central 